\title{
PENSANDO CULTURAS AMERÍNDIAS: EXPERIÊNCIAS DE UM PROJETO DE ENSINO E ESTRANHAMENTOS ${ }^{1}$
}

THINKING INDIGENOUS PEOPLES:

A TEACHING AND ESTRANGEMENTS PROJECT

BASTOS, Danielle ${ }^{2}$

\begin{abstract}
RESUMO
Este artigo analisa um caso particular - a discussão de um projeto sobre ensino de culturas ameríndias em um instituto de aplicação do Rio de Janeiro. As aulas concentram em sua maior proporção alunos do primeiro segmento do Ensino Fundamental e alunos bolsistas da graduação. A ideia central é esboçar um relato de experiência comentando os encantamentos e desvios das atividades do ensino indígena para a educação básica. 0 ensino de culturas ameríndias, as questões fluídas e híbridas de migração de suas culturas fomentam uma quantidade expressiva de contextos e universos distintos reunidos. $O$ ensino a partir da ótica dos autores ameríndios (BANIWA, 2011; BENITES, 2012; KOPENAWA, 2010) e fundamentação em uma literatura pós-colonial (BHABHA, 1996, 2014; CHAKRABARTY, 1997, 2010; DASS, 2011) expressam parte diferencial deste projeto que se pretende "descolonizador". A escolha do material didático, sugestões de atividades, os estranhamentos e curiosidades surtidos das aulas do projeto, nesse contexto, sustentam a questão central deste artigo.
\end{abstract}

\footnotetext{
${ }^{1}$.O projeto de Iniciação à Docência "Pensando Culturas Ameríndias" iniciou no ano de 2016 como desdobramento da pesquisa de doutorado da autora entre os Guarani Mbyá, populações indígenas viventes no estado do Rio de Janeiro. O projeto tem fomento pelo departamento de Estágio e Bolsas CETREINA/UERJ. Seu público atende aos alunos do primeiro segmento do Ensino Fundamental do instituto CAp/UERJ. Foi recentemente premiado com menção honrosa no Prêmio Fernando Sgarbi de Graduação da mesma instituição. O mesmo é vinculado ao projeto "Entre a terra e o céu ameríndio: currículo, cultura e diferença", financiado pela FAPERJ, ambos sob a coordenação da autora. O projeto compreende atualmente dois bolsistas de Iniciação à Docência e uma bolsista de Iniciação Científica. Destaco que autora possui autorização de imagem e voz, portando Termo de Consentimento Livre Esclarecido (TCLE) para todas as imagens e depoimentos expressos neste artigo. Os nomes e identidades dos mesmos não foram declaradas.

2 É Professora Assistente (Dedicação Exclusiva) da Universidade do Estado do Rio de Janeiro (UERJ) no Instituto de Aplicação Fernando Rodrigues da Silveira (CAP - UERJ); doutora em Educação (PROPED /UERJ) ; bolsista Capes / Proex; Mestre em História Social (PPGHS /UERJ - 2011) e possui graduação em Pedagogia pela (UERJ - 2008). É membro do grupo de pesquisa Currículo, Cultura e Diferença vinculado ao (PROPED / UERJ), coordenado pela Profa.Dra Elizabeth Macedo. Sua atual pesquisa concentra-se na educação negociada entre os Mbyá (Guarani) do estado do Rio de Janeiro e aplicação da Lei 11.645/2008 na Educação Básica. As pesquisas com influência pós -coloniais e deleuziana abrangem as grandes áreas da Educação, Filosofia e Antropologia. Tem como interesse os assuntos da socialidade, cosmologia, alteridade, processos de escolarização e currículo entre os povos ameríndios viventes no território brasileiro e hispânico -americano.
} 
e-Mosaicos - Revista Multidisciplinar de Ensino, Pesquisa, Extensão e Cultura do Instituto de Aplicação Fernando Rodrigues da Silveira (CAp-UERJ) V. 7 - N. 16 - DEZEMBRO 2018 - ISSN: 2316-9303

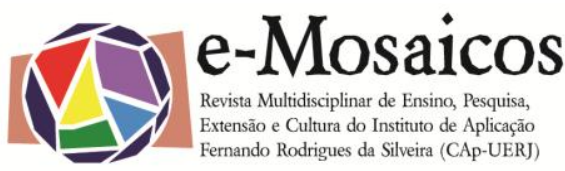

DOI: $10.12957 /$ e-mosaicos.2018.30008

PaLAVRAS-ChaVe: Ensino; Estranhamento, Culturas Ameríndias

\section{ABSTRACT}

This article analyzes the discussion of a project on teaching Amerindian cultures in a teachers' training school in Rio de Janeiro. Attending classes are mostly Elementary School students and undergraduate interns. The main idea is to report an experience commenting the incantations and deviations of indigenous activities in elementary schooling. education. The teaching of Amerindian cultures, the fluid and hybrid issues of migration of their cultures foster significant different contexts and universes. Teaching from the perspective of Amerindian authors (BANIWA, 2011, BENITES, 2012, KOPENAWA, 2010) substantiated by postcolonial literature (BHABHA, 1996, 2014; CHAKRABARTY, 1997, 2010; DASS, 2011) reflect here a differential which intends to be "decolonizing". The choice of didactic materials, suggestions of activities, estrangements and assorted curiosities from the classes support the central question in this article.

Keywords: Teaching; Estrangements; Amerindian cultures

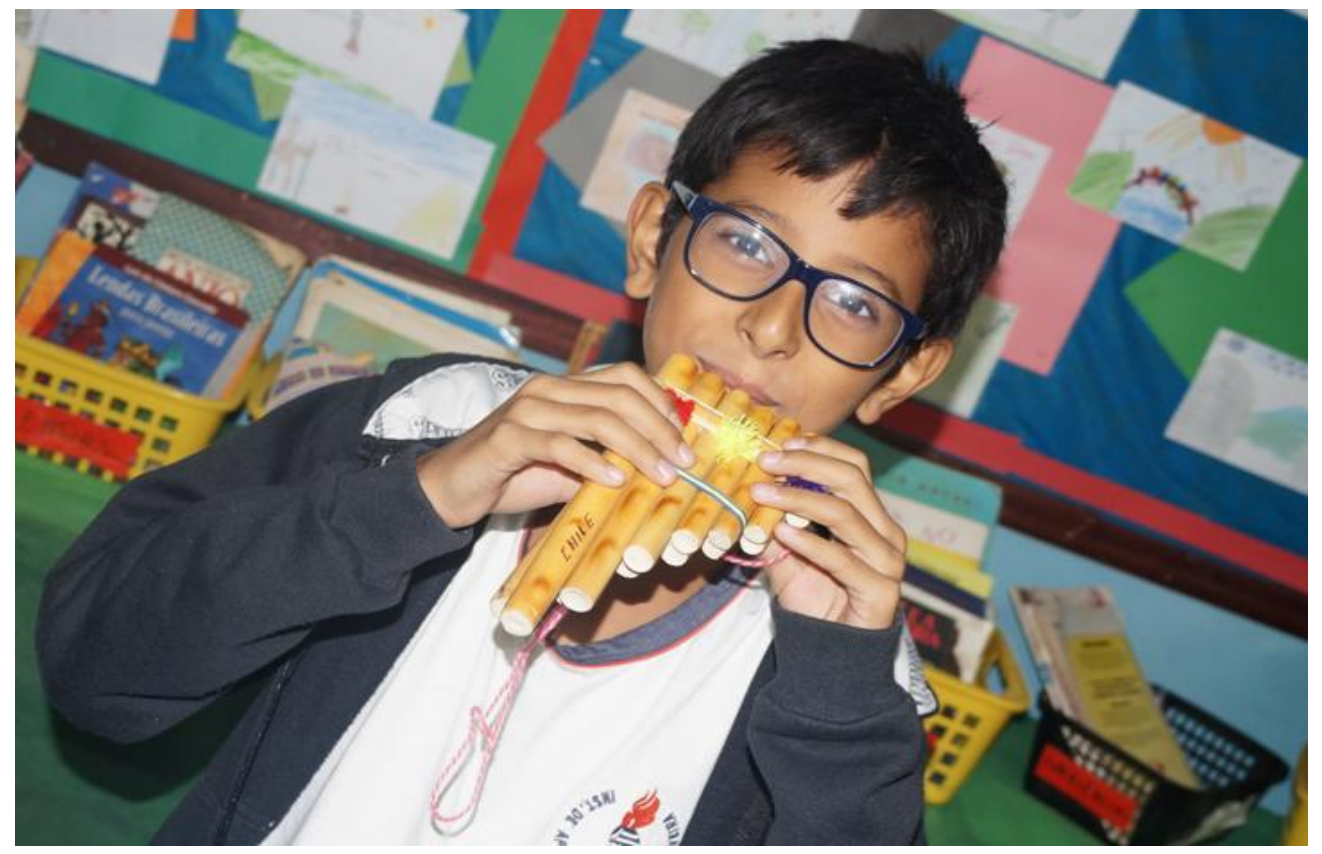

Fig. 1 Kaio (aluno do $4^{\circ}$ ano Cap/UERJ), mostra de flauta Mapuche 


\section{INTRODUÇÃO}

Este artigo narra as experiências de um projeto de ensino sobre culturas ameríndias para crianças do primeiro segmento do Ensino Fundamental, lecionado em um instituto de educação da Universidade Estado do Rio de Janeiro. A especificidade do ensino sobre sociedades ameríndias espelham culturas que abrangem mais de 250 culturas distintas e 188 línguas diferentes; algumas, muitas vezes não comunicantes entre si dentro do conglomerado latinoamericano (CEPAL 2012; FUNASA, 2010). Os ameríndios em larga medida permeiam territórios e intercambiam rotas, transitando por diferentes estados e países, circulando por culturas e sociabilidade variada (VIVEIROS DE CASTRO, 2012a, 2012b; LITAIFF, 1999). O projeto de Iniciação à Docência "Pensando Culturas Ameríndias", partindo deste conhecimento, teve como objetivo contribuir com a pesquisa sobre suas sociedades, usos, costumes assim como analisar as experiências deste tipo de ensino na educação básica. O foco foi oferecer um estudo "ameríndio" mapeando suas transitoriedades em distintos países, línguas e rotas.

Passados oitos anos da Lei $11.645 / 2008^{3}$, que tornou obrigatório o ensino de culturas indígenas na educação básica em âmbito nacional, observamos que é propício, passado cerca de uma década, que aprofundemos a discussão sobre como a legislação vem sendo vivida, como suas re-narrações, apontamentos foram visibilizados (DASS, 2011). Em nosso caso, o artigo, explora, porém, um aspecto particular - concentramos o objeto no Instituto de Aplicação Fernando Rodrigues da Silveira, conhecido como CAp -UERJ. O instituto é reconhecido como uma instituição de excelência em educação básica e em formação de professores (OLIVEIRA, 2014). O termo excelência, remete a inúmeras discussões em termos de aplicação, escala, parâmetro e consequentemente os vazios e silêncios que os parâmetros não mencionam, como a elevada taxa de evasão e jubílio para ser mantido este mesmo padrão. Não avançaremos por ora nesta discussão, embora, quero sublinhar que o instituto tem uma quantidade considerável de pesquisadores e alunos que exploram as particularidades e afastamentos dessa condição de "excelência" na relação com o entorno dos alunos, assim como docentes (ALMEIDA, 2016; OLIVEIRA, 2014).

A intenção da localização no instituto, portanto, expressa um relato de experiência, tanto quanto minha atuação vivível na instituição. Não há necessariamente, a intenção neste artigo, advirto ao leitor desde agora, de marcar o projeto como um modelo a ser seguido ou consubstâncializado como padrão por grupos ou instituições de ensino. Como observo posteriormente, uma ideia de prescrição e objetificação do que deve ser vivido nos contextos escolares, assim como prescrição de modelos e métodos "eficazes" de ensino organizados previamente (BALL, 1997, 2012; MILLER, 2010; 2012; MACEDO, 2012), são

\footnotetext{
${ }^{3}$ Esta lei é uma incorporação de outra lei predecessora, 10.634/2004, que promulga a obrigatoriedade do ensino de História e culturas africanas.
} 


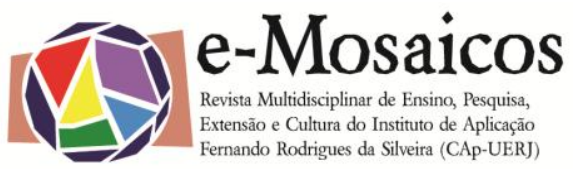

DOI: $10.12957 /$ e-mosaicos.2018.30008

compreensões qual, tendo teoricamente me afastar (BASTOS LOPES, 2012, 2014; OLIVEIRA E BASTOS LOPES, 2016). Ao contrário dos relatos alegres com práticas docentes que funcionam (MILLER, 2012), a intenção central do artigo, nesse contexto, evidencia a sedução e estranhamento dos sistemas ameríndios e sua linguagem distinta apresentado a crianças de seis a nove anos. Esse diagnóstico "enigmático" com relação aos antigos e atuais mundos ameríndios atravessa os escritos e cotidiano das aulas, nos defrontam com um outro ponto de narrativa e inflexão da linguagem para ensinar, experimentar outros sistemas de pensamento opositores aos "nossos". Este aspecto incongruente entre nossa língua e a do "outro"- ameríndio (VIVEIROS DE CASTRO, 2012a), sintetizam, portanto, nosso maior desafio.

\section{MUNDOS POSSÍVEIS AMERÍNDIOS, DESAFIOS DE UMA INTERCULTURALIDADE}

De acordo com a UNESCO (2015), a noção de interculturalidade é responsável por uma nova tensão conceitual que atravessa o debate latino-americano. $\mathrm{O}$ termo propõe uma reparação da desigualdade, indo de proposições que marcam uma identidade intercultural essencial e autêntica, a leituras de interculturalidade ${ }^{4}$ híbridas e que se transportam. Foi em meio a esse interlúdio que o termo divulgado pelas reformas curriculares ocorridas durante os anos 1990 (LOPES E MACEDO, 2011), assim como legislações que tornam obrigatório o ensino das culturas indígenas em contexto nacional, tem conseguido a problematização do ensino e irrupção das identidades estereotipadas. Tal ponto, é positivo para o ensino acerca das sociabilidades não ocidentais. Entretanto, a questão que o projeto em questão, tanto quanto minhas experiências interrogam, dizem respeito a certa ocidentalização do conceito de interculturaliade desposado nos contextos escolares.

Em vez de olhar para o contraste apenas no nível legislativo quero, levar, o argumento, portanto, em outra direção: A interculturalidade tem aparecido como elemento chave para as lacunas do ensino indígena ou para falta do conhecimento sobre os mesmos. Em um estudo redigido por autores ameríndios sul-americanicistas e norteamericanos (BANIWA, 2011; BENITES, 2012; S. BENITES, 2015; WILDCAT,2013), observou-se, que os materiais oferecidos ao ensino de culturas indígenas, por exemplo, em grande parte fundamentam-se em linguagem humanista

\footnotetext{
${ }^{4}$ A concepção de interculturalidade que discuto aqui é a fundamentada por órgãos como a UNESCO e outras políticas interamericanas da América Latina (CEPAL, 2012), naturalmente como a própria UNESCO (2015) ressalta o termo passa por inúmeras apropriações e leituras que envolvem autores de diferentes abordagens e campo distintos (CANDAU, 2011; MCLAREN, COLE, RIKOWSKI, 1999). Não iremos neste artigo explorar uma revisão de literatura destes autores e conceito, entretanto, além da entrevista com Melià (BASTOS LOPES, 2016) qual o autor ressalta especificamente as problemáticas do conceito, sugiro ver a publicação "Multiculturalismo Crítico: uma aproximação", artigo qual me debrucei sobre a revisão desta literatura e autores que abordam o conceito (BASTOS LOPES, 2012).
} 
DOI: $10.12957 /$ e-mosaicos.2018.30008

ou universal ${ }^{5}$. A presença dos autores indígenas nestes materiais é espaçada, apesar do esforço recente das obras na abordagem atualizada dos estudos americanicistas e antropológicos (VIVEIROS DE CASTRO, 2012a). Argumento, portanto, que embora as concepções de interculturalidade e procura por uma representação mais autêntica, tanto quanto "original" dessas representações nos contextos escolares, ainda restringimos as culturas e sociabilidade ameríndia em uma linguagem normativa ou "desencantada", própria da temporalidade ocidental (APPADURAI, 1996; BHABHA,1994; DASS, 2011) Como adverte Chakrabarty (1992, 2009, 2010) -quando o " sobrenatural" de culturas não ocidentais, participa ativamente da circulação do Ocidente contrastam-se, em primeiro plano, os efeitos violentos de uma gramática etnológica normativa que estrutura os conhecimentos e suas intenções em uma lógica antropocêntrica e "desencantada". O autor questiona igualmente o uso acadêmico de categorias genéricas, que pretendem referir-se tanto a objetos, quanto a conceitos abstratos elaborados pelos grupos sociais não ocidentais que abordam termos distintos, por vezes, divergentes daqueles utilizados pelas ciências humanas em geral. Destaco aqui, portanto, minha entrevista com Bartomeu Melià (BASTOS LOPES, 2016); um dos primeiros autores a escrever sobre a educação intercultural indígena no Brasil e América Latina. Entre outros pontos que analisam a interculturalidade (aproximação / afastamento), o autor ressalta a qualidade enganosa da mesma quando em sociedades de forte influência ameríndia, auferimos leis que incentivam os indígenas a aprenderem o idioma vernáculo, mas não incentivamos do memso modo a sociedade a conhecer um idioma indígena:

Interculturalidade é um termo conceitualmente bom, um conceito válido, entretanto, muito enganoso. Por que enganoso? Porque falamos de interculturalidade e de fato nós oferecemos ao negro, ao índio, ao Outro, oportunidades para que estes possam cursar a nossa cultura, isto é, levamos o que nós consideramos médio ou inferior para estes. Oferecemos fórmulas para assimilar o outro ao nosso modo de ser e isso chamamos de interculturalidade; não se trata de um verdadeiro ato de escuta do outro; apenas possibilitamos um diálogo conosco, mas, não estamos prontos para ouvir; interculturalidade seria nós dialogarmos também com eles, precisaríamos escutar 0 outro $e$ tal fato não acontece. Interculturalidade não é abrir o caminho para o índio aprender português; interculturalidade seria o Brasil inteiro saber uma língua indígena pelo menos. Se de fato existisse interculturalidade, a nossa própria mentalidade aceitaria outros sistemas de vida e outros costumes. Nesse sentido, o índio é muito mais aberto, mais intercultural, porque facilmente passa a nos entender, mas nós dificilmente 0 entendemos. Se a discriminação continuar, não

\footnotetext{
${ }^{5}$ Não me estenderei nas questões dos aspectos humanistas e universais quais muitos textos das políticas de currículo intercultural indígena defendem, entretanto, destaco aqui ao leitor trabalhos anteriores onde abordo mesmo tema (BASTOS LOPES, 2012, 2016).
} 


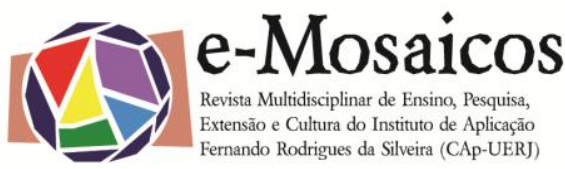

DOI: $10.12957 /$ e-mosaicos.2018.30008

teremos dado o menor passo em matéria de interculturalidade (MELIÀ apudBASTOS LOPES, 2016, p.296).

A questão, entretanto, não se baseia em incluir um outro idioma ameríndio como língua estrangeira obrigatória. É interessante, entretanto, notar como objetificamos a cultura $\mathrm{e}$ as temporalidades ameríndias em modelos universalizantes ${ }^{6}$, mesmo nos valendo da interculturalidade (MELIÀ, 2010). 0 autor enfatiza a importância de se considerarem aspectos das realidades estudadas, assim, aborda a maneira como a ocidentalização encara os sistemas de pensamento nos quais deuses, espíritos e o sobrenatural participam ativamente do mundo dos indígenas (CHAKRABAERTY, 2010, MELIÀ, 2011). Como argumenta Vilaça (2013, 2015), acerca da noção dos ritos Wari', que aqui aproximo particularmente a noções práticas do ensino indígena e participação do mesmo no contexto da educação intercultural: "Não se sai de um ritual com o alívio da solução de um conflito de valores, mas com a certeza da existência de outros tipos de seres e com um determinado tipo de relação estabelecido entre eles; em suma, saímos com um "novo mundo" (VILAÇA, 2014, p. 46). O "novo mundo" que as experiências infletem, com seres, ritos, invisibilidades passam, portanto, pela relação do que não é tão somente contrário ao que é do branco, nem "autêntico", mas acenam como cada cultura e linguagem são distintas umas das outras (KOPENAWA, 2010). É curioso destacar, nesse sentido como o contexto escolar e as literaturas indígenas (KOPENAWA E ALBERTA, 2010, BENITES, 2012) desfiam a lógica entre racionalidade e conhecimento / conhecimento e xamanismos que ressoam outros sistemas de pensamento.

\section{EXPERIÊNCIAS E RELATOS DO PENSAR CULTURAS INDÍGENAS}

" Os territórios e países não significam muita coisa então para os mbyá [guarani], se eles têm um outro mundo e um país deles que pega o Brasil, Argentina, Uruguai ..." (Aluna (a), nove anos, $5^{\circ}$ ano do Ensino Fundamental, outubro de 2015)

\footnotetext{
${ }^{6}$ Esta noção universalizante com que apresentamos os povos ameríndios leva-me, portanto, a achar interessante a crítica ao multiculturalismo utilizada por Eduardo Viveiros de Castro (2012a, p .120) para reafirmar justamente os traços contrastivos do pensamento ameríndio em relação às teorias "multiculturalistas" modernas; "-- enquanto os multiculturalismos se apoiam na implicação entre unicidade da natureza e "multiplicidade das culturas" - a primeira garantida pelo humanismo e unidade dos indivíduos -, segunda, a concepção ameríndia a qual denomina de - multinaturalismo suporia, ao contrário, uma unidade do espírito/cultura e uma diversidade dos corpos." A "cultura" ou o sujeito seriam aqui a forma do universal, a "natureza" ou o objeto a forma do particular. Haveria, portanto, para sua explicação, uma única cultura e variabilidade de corpos e "naturezas" por assim dizer.
} 


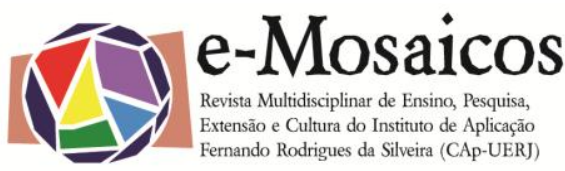

DOI: $10.12957 /$ e-mosaicos.2018.30008

"Minha tataravó foi laçada no mato. Minha mãe me contou. Eu sou ameríndio?" (Aluno (b), oito anos, $3^{\circ}$ ano do Ensino Fundamental, abril de 2016)

"Eu não sabia que os guarani pensavam com o coração e também com o cérebro; o cérebro não ser o principal órgão deles é muito esquisito. " (Aluno (c), nove anos, 40 ano do Ensino Fundamental, março de 2016)

" Eu pedi a meu pai, para comprar um chamador de pássaro igual ao que usamos, tirando o Bem-te-vi que é o mais fácil eu já aprendi a fazer o som de outros dois " (Aluno (d), oito anos, 30 ano do Ensino Fundamental, maio de 2017)

" Eu desenhei o sol e o Kuaray, não teria lógica desenhar o sol mbyá sem o espírito dele" (Aluna (e), oito anos, $3^{\circ}$ ano do Ensino Fundamental, maio de 2017) ${ }^{7}$

Passemos ao desenvolvimento das aulas. As falas e estranhamento das interlocuções acima apresentam parte de outro mundo de significação e ruídos heterogêneos provocam no contexto escolar. O trabalho "Pensando Culturas Ameríndias" abrangeu alunos, bolsistas, orientadores, não havendo restrição por faixa etária ou outro critério seletivo. Como comum às aulas do instituto os alunos têm acesso a textos variados, não tendo obrigatoriamente a adaptação do material letivo a idades específicas ou outro critério determinado. Os alunos leem periódicos, sites, tanto quanto artigos científicos. A não didatização de um material objetificado, adaptado a determinada faixa etária influencia o cotidiano do instituto, assim como as particularidades em relação ao material oferecido aos alunos e outros pesquisador.

Trabalhamos com a concepção interdisciplinar, e associação do ensino com a pesquisa científica. Os alunos estabelecem-se em grupos, em rodas de conversas e não falas e a trabalhar os conteúdos através de situações que façam sentido a partir de suas trocas e afetamento. Além do material bibliográfico os alunos tiveram acesso a artefatos e peças musicais, arte plumária das populações Mbyá (Guarani) do Rio de Janeiro. Os alunos manuseiam as peças e artefatos durante as aulas, elaborando paralelamente um trabalho de curadoria e organização com os mostruários Muitos praticam o atirar o arco e flecha, produzem som com os instrumentos ameríndios e elaboram estudos a partir do desenho e grafismo das cestarias.

7 A questão do pensamento e cosmologia guarani qual aluno se refere, destaca o fato que para os mbyá o cérebro é apenas uma extensão corporal, onde o órgão pensante podemos dizer em uma "tradução equivocada" (VIVEIROS DE CASTRO 2012), é centralmente o py'a (coração). Estes e outros temas da cosmologia guarani abordo em textos anteriores: BASTOS LOPES $(2012,2016)$. 


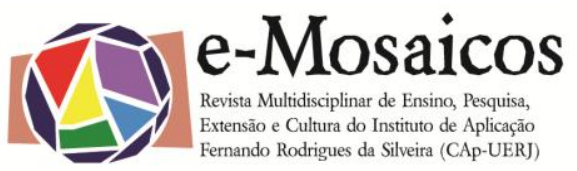

DOI: $10.12957 /$ e-mosaicos.2018.30008

Os trabalhos são direcionados tanto quanto produzidos em conjunto. A possibilidade de estabelecer o diálogo entre a leitura e a observação das peças, acervo fotográfico constitui um dos traços cruciais das atividades. A participação tem me permitido acompanhar o estranhamento e curiosidade originada de cada situação ou grupo específico; tanto do grupo de alunos quanto dos bolsistas. O exercício da pesquisa, argumento que suscita não apenas o recebimento da informação, mas a reflexão do material e artefatos recebidos analisados ou catalogados. Mais do que reafirmar o precário em relação ao ensino sobre culturas ameríndias, observo que um aprofundamento do como esse mesmo universo de culturas vem sendo apresentado na prática, no cotidiano das aulas, repercuti como um dos pontos de sedução e curiosidade do ensino indígena.

\section{POSSIBILIDADES DO MATERIAL DIDÁTICO}

"Em um dos dias de aula fui surpreendida com um aluno que me tomara o apanhador de pássaros guarani (nhandukya), e flertava com outros instrumentos igualmente exóticos que acomodava em minha bolsa. Havia o trazido por acaso, na ocasião de uma das visitas que faço com certa frequência aos mbyá (Guarani) do Rio de Janeiro. Grupo que tenho proximidade com suas famílias e parentes a mais de dez anos. Naturalmente, guardei os outros apetrechos e artefatos que portava em minha bolsa "suigeneris" para não "perder" mais outros. Para minha surpresa os sons tirados pelo aluno "bulidor" do instrumento eram senão idênticos, muito semelhantes aos que experimento com frequência entre os guaranis. Na aula seguinte voltei então com outros artefatos, dessa vez um arco e flecha. As flechas como os arcos suscitaram uma quantidade de questionamentos, discussões e apresentação de outro mundo material. Estas lembranças vagas, aqui um pouco desajustadas, de meu início de docência em uma escola pública do Rio de janeiro formam, portanto, o início do meu afetamento com outros modelos e formas de material didático possível".

Para o trabalho em sala de aula, portanto, pode ser proveitoso associar o passado com o contemporâneo. Uma boa opção é o estudo comparativo entre imagens dos grupos do período jesuítico-colonial e iconografias recentes das populações ameríndias presente no território latinoamericano (BESSA FREIRE, 2012, 2014; CEPAL, 2012). O reconhecimento da localização antiga dos territórios 
DOI: $10.12957 /$ e-mosaicos.2018.30008

contrastado com a localização dos grupos atuais, permite a visualização de uma variabilidade de aspectos como a convergência ou afastamento dos grupos, assim como alterações em seus significados, inversões culturais ocorridas nos novos espaços. Neste contexto, discutimos as transformações, exilio e migração de um grupo ou região (BASTOS LOPES, 2014).

Por toda América Latina estão difusos meios de informação sobre lugares, horticulturas, animais, incluindo nomes de rua, bairros escritos em línguas ameríndias ou africanas (BARTOLOMÉ, 2010; BESSA FREIRE, 2014). O conteúdo semântico pode ser explorado em aula, evocando contextos de determinada localidade ou ensinando re-narrações dos conhecimentos transmitido durante os séculos, mas, despercebido em nosso cotidiano. Sites como Pró-Índio Uerj (www.proindiouerj.blogspot.com.br), produzido pelo professor José Bessa Freire, Escritores Indígenas (escritoresindigenas.blogspot.com.br), Portal das Memórias de África e do Oriente (memoria-africa.ua.pt), e o da escritora Eliane Potiguara, (elianepotiguara.blogspot.com.br) exibem indicações interessantes, com diferentes materiais, fotografias, áudios e entrevistas tornando mais dinâmico e inteligível o acesso.

O trabalho com o material didático no CAp-UERJ particularmente foi organizado com grande parte desses sites e outros materiais interativos. Utilizamos o material fruto das pesquisas, mais do que o uso do livro didático indicado por programas nacionais exemplarmente (ALMEIDA, 2016; OLIVEIRA, 2014). O fluxo do uso, portanto, aparece como pivô da ideia de um currículo menos normativo e mais aberto a possibilidades do inesperado das aulas (MILLER, 2010,2014); assim como a participação dos professores, alunos e outros envolvidos.

Essa relação com o material não objetificado é proeminente em outros anos de escolaridade e projetos do instituto. Os docentes com auxílio dos bolsistas compõem a maioria do material utilizado (BASTOS LOPES, 2012,2014; OLIVEIRA, 2014). O registro e os derivados das aulas: anotações de campo, conferências, vídeos, saraus, compõem parte do trabalho com o material didático.

\section{CONCLUSÃo}

A ideia, podemos concluir, portanto, não foi objetificar culturas indígenas em materiais didáticos, mas, sim instigar outras possibilidades de experiências e acervo. Algumas observações gerais são então necessárias. Entre os grupos dos alunos, bem como em qualquer outo segmento social obtemos diversos entendimentos sobre a cultura e sentidos sobre a religiosidade, não necessariamente homogêneos ou integrados. Infelizmente, há poucos estudos que abordam o assunto em especifico (BANIWA, 2011; BENITES, 2012; OLIVEIRA E BASTOS LOPES, 2016). Porém, o ponto que quero enfatizar aqui é a importância do contextualizar a relação com o sobrenatural nos significados do mundo ameríndio ou pós-mundo --- deve-se, portanto, discutir o sobrenatural e noções que desdobram a lógica do humano /não 


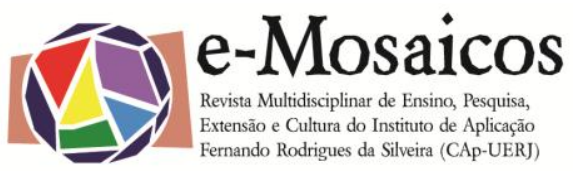

DOI: $10.12957 /$ e-mosaicos.2018.30008

humano no processo de relação com as culturas. A maturação das literaturas indígenas inicia com o acúmulo dos mundos e rituais, e é encerrada com os "moralismos" do corpo indígena. Ou seja, o estranhamento marca tanto o começo quanto o final das aulas; mostrando um processo de desdobramento implicado em um novo mundo e perspectivas contraditórias/ opositoras sobre alma, corpo, humanidade que as experiências e re-narrações exibem.

Como argumentou Viveiros de Castro (2012a, 2012b), noção da identidade e pessoa indígena não se materializa pelo sentido de oposição humanidade $x$ animalidade. Complica-se uma divisão definida entre o que é razão e o que é o objeto, onde se inicia ou termina o espiritual. O limite que define essa diferenciação é representado por lógicas sensíveis, que independe de um objeto frio, produzido pelo trabalho, etc. Em suma, os artefatos têm vida e fazem parte da ligação do indivíduo com o mundo (APPADURAI, 1996; CHAKRABARTY, 1997). E comum argumentos, nesse sentido, que defendem um ensino bilíngue e específico, mas pouco discutimos os indicativos de um índio ocidentalizado que preexiste nas políticas interculturais. A ligação entre o efeito alienador do cheiro do sangue e a separação entre os espíritos de animais/plantas, narrada em mitos por toda a Amazônia, exploram os limites dos novos mundos que os alunos aprendem, discutem, lançam o seu questionamento. O contato com a obra dos autores indígenas, portanto, argumento, abre possibilidades para outros contextos, outras formas de significação (VILAÇA, 2013, 2015; VIVEIROS DE CASTRO, 2012a) no ensino básico.

\section{REFERÊNCIAS}

ALMEIDA, Monica A. O. Ação afirmativa de corte racial na educação básica em uma escola de excelência: a experiência do Instituto de Aplicação Fernando Rodrigues da Silveira - CAp/UERJ. Tese de doutorado (Educação). Pontifícia Universidade Católica do Rio de Janeiro -PUC RJ. Rio de Janeiro, 2016.

APPADURAI, Arjun. The Social Life of Things. New York: University Press, 1996.

BALL, Stephen. Educational reform: a critical and post-structural approach. Buckingham: Open University Press, 1997.

. Global education. In: new policy networks and the neoliberal imaginary. New York: Routledge, 2012.

BANIWA, Gersem Jose dos Santos L. Educação para manejo e domesticação do mundo: entre a escola ideal e a escola real. Os dilemas da educação escolar indígena no Alto Rio Negro. Tese de doutorado (Educação). Universidade de Brasília - UNB. Brasília, 2011. 
DOI: 10.12957/e-mosaicos.2018.30008

BASTOS LOPES, Danielle. Multiculturalismo crítico: uma aproximação. Em tempo de História (digital), v. 21, p. 205-210, 2012.

. Não para os clichês. Alteridade indígena e africana ainda é pouco conhecida pelos professores e retratada de forma superficial nos livros didáticos. Revista de História da Biblioteca Nacional, v. 103, p. 70 - 73, 2014

Entre a terra e o céu guarani: uma conversa com B. Melià. Espaço Ameríndio (UFRGS), v. 10, p. 289-298, 2016.

BENITES, TONICO. A escola na ótica dos Avá Kaiowá: impactos e interpretações indígenas. Rio de Janeiro: Contracapa, 2012.

BESSA FREIRE, J. R. EJA Guarani - Além e Aquém do Bilinguismo. In: BARROS, Armando Martins e SANTOS, Fernanda Muniz e BARBOSA, dos Santos Grabriela (Org.) EJA Guarani. O Registro de uma história e perspectivas atuais. Volume II. Rio de Janeiro: Ed. E-papers, 2012. 44-46, 2014.

Índio falou, tá falado. Revista de História da Biblioteca Nacional, v. 9, p.

BHABHA, Homi. K. The location of culture. New York: Routledge,1994.

BRASIL. Lei no 11.645, de 10 de março de 2008. Diário Oficial da República Federativa do Brasil. Brasília: Senado Federal, 2008.

CANDAU., Vera M. Diferenças culturais, cotidiano escolar e práticas pedagógicas. Currículo sem Fronteiras, v.11, n.2, p.240-255, Jul/Dez 2011.

CEPAL (Comissão Econômica para América Latina e o Caribe) e UINICEF (Fundo das Nações Unidas para Infancia). Guia para estimar la pobreza infantil. Informacion para avanzar em el ejercicio de los derechos de los ninõs, ninãs y adolescentes. Santiago: abril, 2012.

CHAKRABARTY, Dipesh. Postcoloniality and the Artifice of History: Who Speaks for "Indian" Pasts? Representations. Special Issue: Imperial Fantasies and Postcolonial Histories, n. 37, winter, p. 100-122, 1992.

2009.

. The climate of history: four theses. Critical Inquiry, n. 35, v. 2, p. 97-222,

. Una pequeña historia de los estudios subalternos. In: SANDOVAL, Pablo. (Org.). Repensando la subalternidad. Miradas críticas desde / sobre América Latina. Lima, Peru. Instituto de Estudios Peruanos, 2010. 
DOI: $10.12957 /$ e-mosaicos.2018.30008

DAS, VEENA. O ato de testemunhar: violência, gênero e subjetividade. Cadernos Pagu (37), jul/dez, p 9-41, 2011.

FUNDAÇÃO NACIONAL DA SAÚDE (FUNASA). Sistema de Informação e Atenção à Saúde Indígena (Siasi). Demografia dos povos indígenas, 2010. Disponível em: <http://www.funasa.gov.br>. Acesso em março de 2017.

KOPENAWA, Davi e ALBERT, Bruce. La chute du ciel paroles d'um chaman Yanomami. Paris: Paris Plon, 2010.

LITAIFF, Aldo. Les Fils du Soleil: mythes et pratiques des indiens mbya-guarani du littoral du Brésil. Thése. Université de Montréal. Québec, 1999.

LOPES, Alice C e MACEDO, Elizabeth. Teorias de Currículo. São Paulo: Ed. Cortez, 2011.

MACEDO, Elizabeth. Currículo e conhecimento: aproximações entre educação e ensino. Cadernos de Pesquisa. v. 42, n.147, p. 716-737, 2012.

MCLAREN; P E COLE, M.; RIKOWSKI, G. Pós-modernismo in Educational Theory. Education and the Politics of Human Resistance. London: Tufnell Press, 1999.

MELIÁ, Bartomeu. Passado, presente y futuro de la lengua guaraní. Asunción: Ed. CEADUC/ISEHF, 2010.

. Mundo Guaraní. Asunción: BID, 2011.

MILLER, Janet L. Nostalgia for the Future Imagining Histories of JCT and the Bergamo Conferences. Journal of Curriculum Theorizing, vol 26, n. 2, p. 7-23. 2010.

- Teorização do currículo como antídoto contra/na Cultura da Testagem. Revista e-Curriculum, São Paulo, vol. 12, n. 03, p. 243-263, 2014.

OLIVEIRA, Crizan Sasson C. E você não quer, faça matrícula no pagou-passou da esquina. Concepções de currículo e avaliação: diálogos sobre um colégio de excelência. Dissertação de Mestrado (Educação). Universidade do Estado do Rio de Janeiro - UERJ, 2014.

OLIVEIRA, T. R. M.; BASTOS LOPES, Danielle. On the limits of the non/human in the field of curriculum. Curriculum Inquiry, v. 26, p. 1101-1125, 2016.

VILAÇA, APARECIDA M. N. Two or threee things that I know about talking to the invisible. HAU: Journal of Ethnographic Theory, v. 3, p. 359-363, 2013.

. De ritos e Mundos. Debates do Ner, Porto Alegre, v. 15, p 45-48, 2014. 
DOI: $10.12957 /$ e-mosaicos.2018.30008

Do animists become naturalists when converting to Christianity? Discussing an ontological turn. Cambridge Anthropology, vol. 33, p. 3-19, 2015.

VIVEIROS DE CASTRO, E.. Cosmological perspectivism in Amazonia and elsewhere. Hau - Journal of Ethnographic Theory, vol. 1, p. 45-168, 2012a.

- Radical dualism: a meta-fantasy on the square root of dual organizations. Kassel: documenta 13, v. 1, p.1-43, 2012 b.

S. BENITES, Sandra. (Ara Rete). Nhe'ê, reko porã rã: nhemboea oexakarẽ fundamento da pessoa guarani, nosso bem-estar futuro (educação tradicional): o olhar distorcido da escola. Trabalho de conclusão de curso da Licenciatura Intercultural Indígena do Sul da Mata Atlântica. (Educação). Universidade Federal de Santa Catarina -UFSC. Florianópolis, 2015.

UNESCO (Organização das Nações Unidas para a Educação Ciência e Cultura). Desafíos. Boletim de la infancia y adolescencia sobre el avance de los Objetivos de Desarrollo del Milenio. no 14. Santiago, 2015.

WILDCAT, Daniel R. Introduction: climate change and indigenous peoples of the USA. Climatic Change. v.120, p.509-515, 2013.

Recebido em 14 de Agosto de 2017

Aceito em 30 de Agosto de 2018 